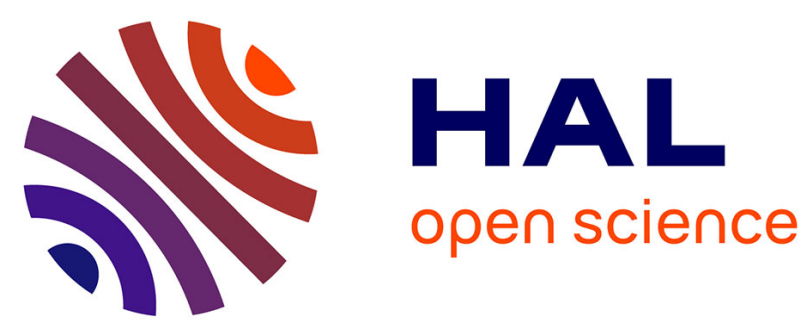

\title{
Characterization of carbon and iron nanostructures synthesized by the DC arc discharge method: influence of the location in the reactor and of the pressure
} Abdeslem Fnidiki, Dany Lemarchand, Etienne Talbot, H. Pascard

\section{- To cite this version:}

Abdeslem Fnidiki, Dany Lemarchand, Etienne Talbot, H. Pascard. Characterization of carbon and iron nanostructures synthesized by the DC arc discharge method: influence of the location in the reactor and of the pressure. European Physical Journal: Applied Physics, 2005, 32 (3), pp.177-185. 10.1051/epjap:2005094 . hal-01331729

\author{
HAL Id: hal-01331729 \\ https://hal.science/hal-01331729
}

Submitted on 21 Dec 2018

HAL is a multi-disciplinary open access archive for the deposit and dissemination of scientific research documents, whether they are published or not. The documents may come from teaching and research institutions in France or abroad, or from public or private research centers.
L'archive ouverte pluridisciplinaire HAL, est destinée au dépôt et à la diffusion de documents scientifiques de niveau recherche, publiés ou non, émanant des établissements d'enseignement et de recherche français ou étrangers, des laboratoires publics ou privés. 


\title{
Characterization of carbon and iron nanostructures synthesized by the DC arc discharge method: influence of the location in the reactor and of the pressure
}

\author{
A. Fnidiki ${ }^{1}$, a, D. Lemarchand ${ }^{1}$, E. Talbot ${ }^{1}$, and H. Pascard ${ }^{2}$ \\ 1 Groupe de Physique des Matériaux, UMR CNRS 6634, Institut des Matériaux de Rouen, Université de Rouen, \\ avenue de l'Université, BP 12, 76801 Saint-Étienne du Rouvray, France \\ 2 Laboratoire des Solides Irradiés, UMR CNRS 7642, DRECAM-CEA, École Polytechnique, route de Saclay, \\ 91128 Palaiseau, France
}

Received: 1st October 2004 / Received in final form: 17 June 2005 / Accepted: 20 July 2005 Published online: 14 December 2005 - (c) EDP Sciences

\begin{abstract}
X-ray diffraction, Mössbauer spectroscopy, Scanning Electron Microscopy (SEM) and Transmission Electron Microscopy (TEM) techniques were used to characterize the Fe-C phases in the soots synthesized by the DC arc discharge method. Various equilibrium and non-equilibrium Fe-C compounds were identified, with fractions depending on both the location in the reactor and the helium gas pressure. The soots obtained are composed of the same five phases (C-graphite, $\alpha$-Fe, $\gamma$-Fe, $\mathrm{Fe}_{3} \mathrm{C}$ and $\mathrm{Fe}_{5} \mathrm{C}_{2}$ ) whatever the helium gas pressure and wherever they are situated in the reactor. However, the location in the reactor has a considerable influence on the size of the particles in the nanostructure. The Fe-C compounds in the Pyrex vessel samples (CL) seem only to be present in the form of nanoparticles embedded in an amorphous gangue, while the water-cooled copper cylinder samples (RS) contain, in addition to these nanoparticles, large composite crystalline particles.
\end{abstract}

PACS. 52.80.Mg Arcs; sparks; lightning; atmospheric electricity - 81.05.Uw Carbon, diamond, graphite 61.18.Fs Magnetic resonance techniques; Mössbauer spectroscopy -61.46.+w Nanoscale materials: clusters, nanoparticles, nanotubes, and nanocrystals $-61.10 . \mathrm{Nz}$ X-ray diffraction

\section{Introduction}

The DC arc discharge method, which is based on the vaporization of graphite by an intense electric arc, has been recognized as a powerful method to produce various carbon nanostructures like fullerenes or nanotubes [1-5]. This method was later developed to produce new kinds of multi-elements nanostructures made up of carbon with additional chemical species. In the composite electrode arc discharge method, these nanostructures are formed from a plasma created between two carbon electrodes, one of which is filled with the additional element [6]. Numerous new kinds of nanostructures have been identified from these experiments like nanowires encapsulated in carbon nanotubes [7-9] or nanocrystallites of elements encapsulated in graphitic or amorphous carbon [10].

A great variety of additional elements have been tested by the arc discharge method including insulators [11], semi-conductors [12], 4f-rare earth elements $[3,13]$ and 3diron transition group metals $[3,14]$. In this paper, we focused our interest on the study of the compounds formed using carbon and iron.

\footnotetext{
a e-mail: abdeslem.fnidiki@univ-rouen.fr
}

In the composite electrode experiments, nanostructures are often non-equilibrium compounds due to the high temperature and the high-temperature gradient conditions present in the reactor. Moreover, due to different geometrical, thermal and pressure conditions at various places of this reactor, the formation processes are expected to be different. As a consequence, the nature and the fraction of the non-equilibrium compounds also depend on the place of levy in the reactor. The aim of this study is to clarify the nature and fraction of the various $\mathrm{Fe}-\mathrm{C}$ nanostructures synthesized by the DC arc discharge method as a function of different parameters like the place of levy or the helium gas pressure in the reactor. The samples were analysed by X-ray diffraction, Mössbauer spectroscopy, SEM and TEM techniques.

\section{Experimental}

Figure 1 shows schematically the experimental set-up used for the synthesis of various nanostructures of carbon and iron. The apparatus is a modified fullerene reactor, in which a composite anode is used. The reactor consists 


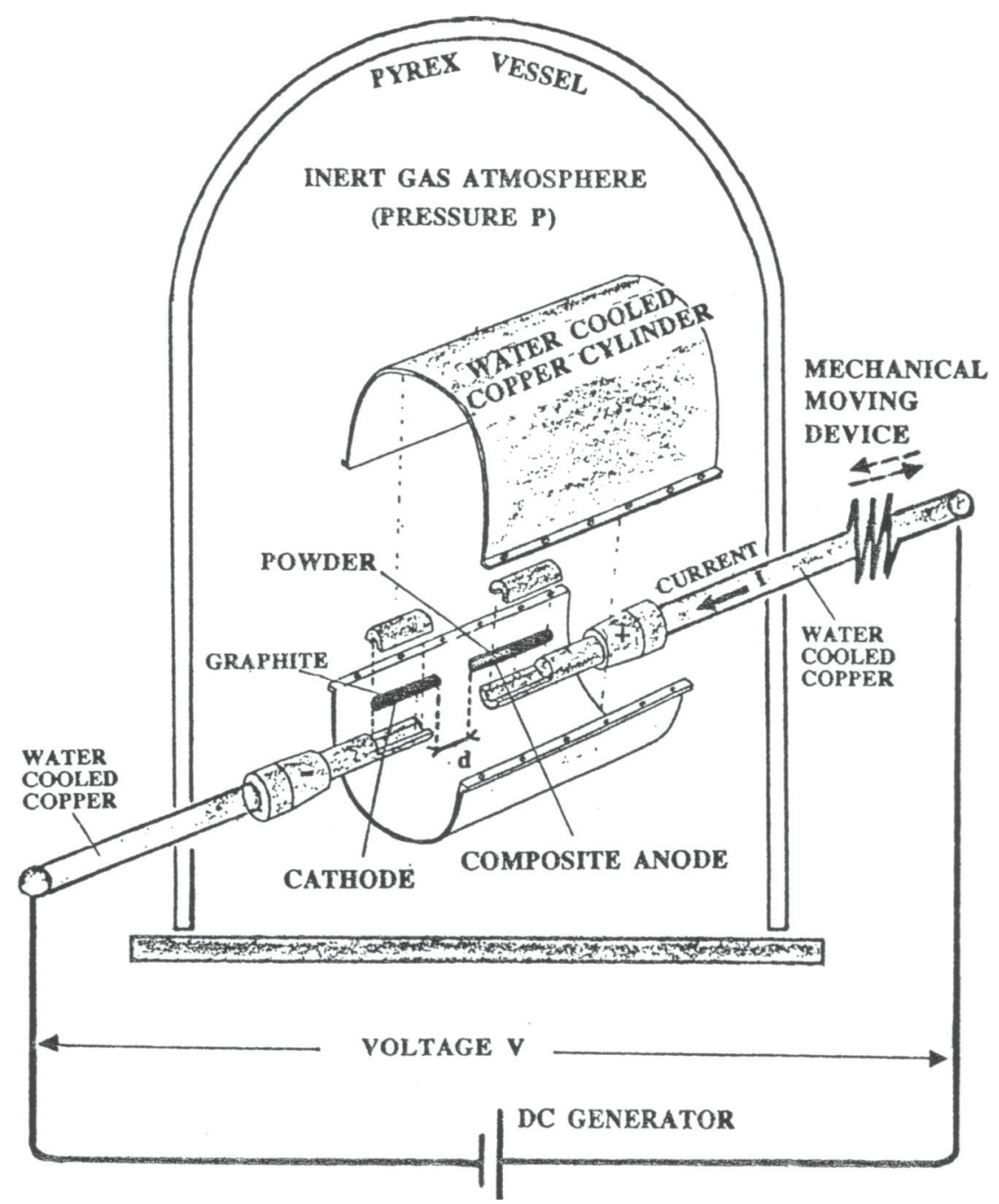

Fig. 1. Schematic drawing of the DC electric-arc-discharge reactor.

mainly of a vacuum chamber, a DC current generator, two water-cooled copper rods to supply the current, a graphite cathode, a graphite-iron composite anode, an electrodemoving device and a water-cooled copper sleeve surrounding the plasma. The vacuum chamber is evacuated with a mechanical vacuum pump and then refilled with a gas (helium) to a static pressure between 0.1 and 0.8 bar. The DC generator is a DC arc welder supplying about $3 \mathrm{~kW}$ during the plasma experiment with a current of around $100 \mathrm{~A}$ and a voltage of around $30 \mathrm{~V}$. The graphite electrodes are fixed on two water-cooled copper rods which supply the current. The cathode is a graphite rod $9 \mathrm{~mm}$ in diameter and $42 \mathrm{~mm}$ in length. The anode is a graphite rod $9 \mathrm{~mm}$ in diameter, $72 \mathrm{~mm}$ in length, with a hole $6 \mathrm{~mm}$ in diameter drilled to a depth of $38 \mathrm{~mm}$ and filled with a mixture of graphite and iron powders. The iron and graphite powders are mixed by choosing a graphite/metal volume ratio of roughly the percolation threshold for the metal (70\% graphite, $30 \%$ iron). One of the copper rods supplying the current is mounted on a mechanical moving device allowing manual adjustment of the distance $d$ between electrodes, typically from $1 \mathrm{~mm}$ to $1 \mathrm{~cm}$. The plasma region is surrounded by a water-cooled copper cylinder about $15 \mathrm{~cm}$ in diameter.

Five samples were synthesized by the DC arc discharge method, with different helium gas pressures and taken at different places in the reactor (Tab. 1).

The samples were analysed by TEM using a JEOL 2000 FX transmission electron microscope operating at $200 \mathrm{kV}$. For TEM observations, the as-obtained Fe-C soot was dispersed in ethanol by ultrasounds. Droplets of the dispersions were then collected on a TEM copper grid covered with a carbon/formvar thin film. Ethanol was then evaporated resulting in an electron-transparent deposit on the film. These preparations on grids were also directly examined in an SEM using a LEO 1530 Field Electron Gun microscope.

The samples were analysed by X-ray diffraction (XRD) measurements using Co $\mathrm{K}_{\alpha}$ radiation $(\lambda=0.1789 \mathrm{~nm})$. Two diffractometers with two different configurations were used: an INEL goniometer equipped with CPS 120 curved position-sensitive detector and a conventional SIEMENS powder diffractometer working in the Bragg-Brentano configuration. 
Table 1. Name of samples synthesized by the arc discharge method, with different helium gas pressures and taken at different places in the reactor.

\begin{tabular}{lll}
\hline Sample & Place in the reactor & Helium pressure (bar) \\
\hline RS 0.1 & Water-cooled copper cylinder & 0.1 \\
RS 0.3 & Water-cooled copper cylinder & 0.3 \\
RS 0.6 & Water-cooled copper cylinder & 0.6 \\
CL 0.3 & Pyrex vessel & 0.3 \\
CL 0.6 & Pyrex vessel & 0.6 \\
\hline
\end{tabular}

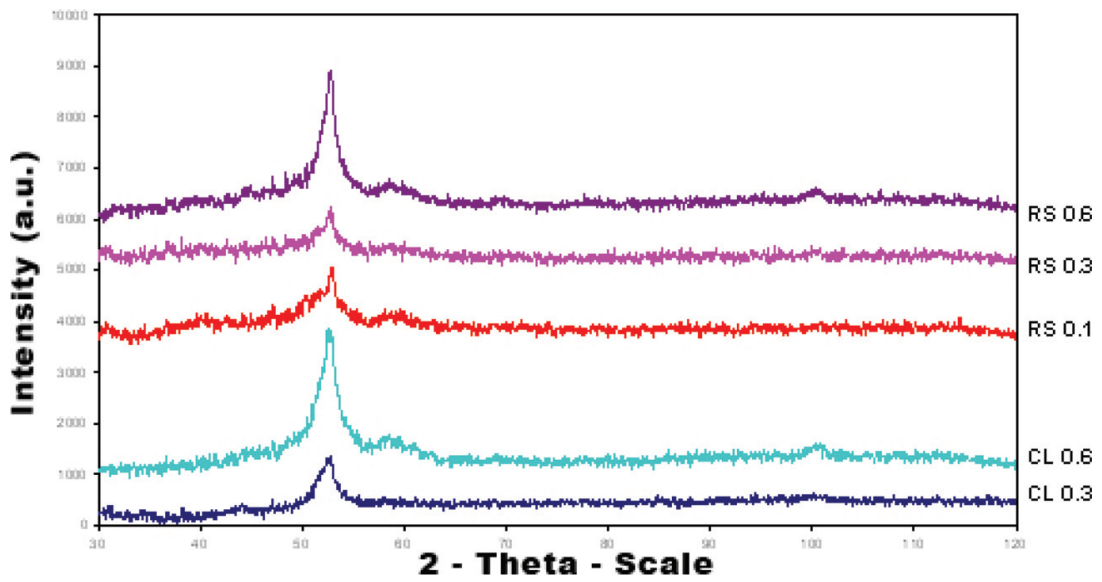

Fig. 2. High-angle X-ray diffraction patterns of the different samples.

Table 2. The most intense diffraction peaks of iron-carbon phases indexed in the JCPDS data file [16].

\begin{tabular}{llll}
\hline & $d(\mathrm{~nm})$ & $h k l$ & $2 \theta$ with $\mathrm{Co} \mathrm{K}_{\alpha}$ radiation $\left(^{\circ}\right)$ \\
\hline$\alpha-\mathrm{Fe}$ & $0.203 \pm 0.001$ & 110 & $52.4 \pm 0.1$ \\
& $0.117 \pm 0.001$ & 211 & $99.7 \pm 0.1$ \\
\hline$\gamma-\mathrm{Fe}$ & $0.209 \pm 0.001$ & 111 & $50.7 \pm 0.1$ \\
& $0.181 \pm 0.001$ & 200 & $59.3 \pm 0.1$ \\
\hline $\mathrm{Fe}_{3} \mathrm{C}$ & $0.201 \pm 0.001$ & 031 & $52.8 \pm 0.1$ \\
& $0.207 \pm 0.001$ & 102 & $51.3 \pm 0.1$ \\
\hline $\mathrm{Fe}_{5} \mathrm{C}_{2}$ & $0.205 \pm 0.001$ & 510 & $51.7 \pm 0.1$ \\
& $0.208 \pm 0.001$ & 021 & $50.9 \pm 0.1$ \\
\hline $\mathrm{C}_{\text {graphite }}$ & $0.335 \pm 0.001$ & 002 & $30.9 \pm 0.1$ \\
& 0.203 & 101 & $52.2 \pm 0.1$ \\
\hline
\end{tabular}

Mössbauer spectroscopy (MS) analyses were performed at room temperature in transmission geometry by using a ${ }^{57} \mathrm{Co}$ source in a rhodium matrix, the $\gamma$ beam direction being perpendicular to the sample plane. With transmission mode, the samples can be analysed across their whole thickness. The spectra obtained were fitted with a least-squares technique using MOSFIT program [15]. The isomer shift $(I S)$ at the ${ }^{57} \mathrm{Fe}$ nucleus is given relative to $\alpha$-Fe at room temperature.

\section{Results and discussion}

\subsection{X-ray diffraction analysis}

The high-angle X-ray diffraction range has been investigated in order to perform a structural identification of the different phases existing in the five samples synthesized with different helium gas pressures and taken at different places in the reactor.

Figure 2 shows the high-angle X-ray diffraction patterns for these five samples obtained with the INEL diffractometer. The spectra exhibit characteristic peaks in the diffraction angle domain $30-120^{\circ}$. Except for the intensity of peaks, the different spectra present the same general picture indicating that the five samples are composed of the same phases, whatever the helium gas pressure and the place in the reactor from which the sample comes. The different spectra show a main peak in the $2 \theta$ domain $48-54^{\circ}$ and another peak located at $100^{\circ}$.

These peaks were identified by comparison with the crystallographic data on the Fe-C binary compounds indexed in the JCPDS data file [16] (Tab. 2). As a result of this analysis, the main peak cannot be non-ambiguously indexed. It could be attributed simultaneously to the most intense diffraction peaks of several possible compounds that are present in the same angular range: (101) of 


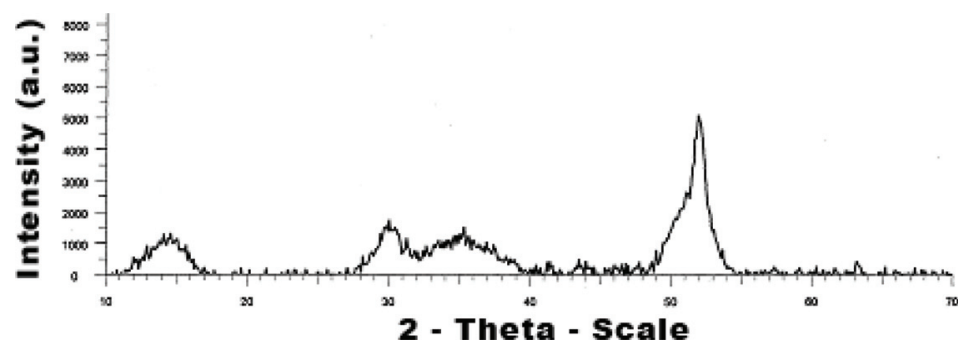

Fig. 3. X-ray diffraction pattern in the Bragg-Brentano configuration $\theta-2 \theta$ of CL 0.3 sample in the $2 \theta$ domain $10-70^{\circ}$.

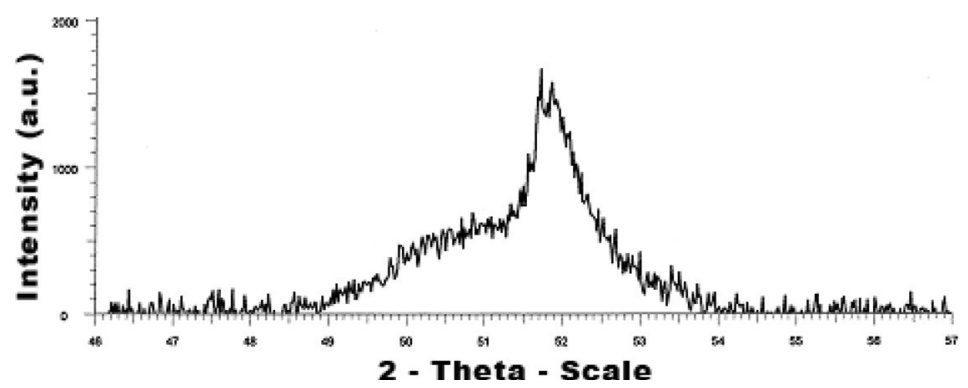

Fig. 4. High angle X-ray diffraction pattern in the configuration $\theta-2 \theta$ in the $2 \theta$ domain $48-54^{\circ}$ of the main peak corresponding to sample CL 0.3 .

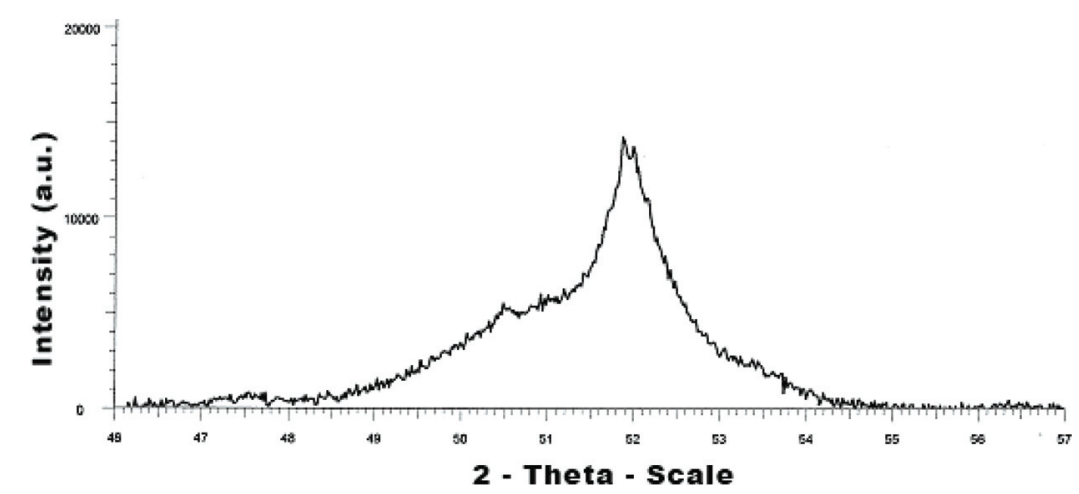

Fig. 5. High angle X-ray diffraction pattern in the configuration $\theta-2 \theta$ in the $2 \theta$ domain $48-54^{\circ}$ of the main peak corresponding to sample RS 0.3 .

graphitic C, (110) of $\alpha$-Fe, (111) of $\gamma$-Fe, (031) and (102) of $\mathrm{Fe}_{3} \mathrm{C}$ or (510) and (021) of $\mathrm{Fe}_{5} \mathrm{C}_{2}$. Indeed, the lattice spacings corresponding to all these compounds give a single peak in the narrow $2 \theta$ domain $50.7-52.8^{\circ}$. The second peak situated at $2 \theta=100^{\circ}$ corresponds to the (211) reflection of $\alpha$-Fe. These results obtained from X-ray diffraction analysis clearly confirm the presence of $\alpha$-Fe.

To obtain the best angular resolution, we have performed X-ray diffraction experiments with the SIEMENS diffractometer in the Bragg-Brentano configuration $\theta-2 \theta$. Figure 3 shows the spectrum of a sample (CL 0.3) in the whole angular range of diffraction. We observe the main peak as well as three other peaks situated at $14^{\circ}, 30^{\circ}$ and $35^{\circ}$. The peak at $2 \theta=30^{\circ}$ may correspond to the $(002)$ reflection of the graphite phase. We have not been able to identify the peaks situated at $2 \theta=14^{\circ}$ and $2 \theta=35^{\circ}$.

In order to obtain more details on the main peak, we performed high angular X-ray diffraction experiments in the $2 \theta$ domain $48-54^{\circ}$ of the main peak for samples CL 0.3
(Fig. 4) and RS 0.3 (Fig. 5). Indeed, the main peak appears as a convolution of 2 intense peaks and a less intense broad peak. These different contributions are thought to correspond to the five previously-mentioned phases.

In summary, the X-ray diffraction data show a main peak that can contain up to five phases (C-graphite, $\alpha$ $\mathrm{Fe}, \gamma-\mathrm{Fe}, \mathrm{Fe}_{3} \mathrm{C}$ and $\mathrm{Fe}_{5} \mathrm{C}_{2}$ ). These results clearly confirm the presence of $\alpha$-Fe, but it is difficult to conclude on the presence and the proportions of the other four phases in the samples.

\subsection{Electron microscopy observations}

The soots were dispersed on a thin carbon/formvar support film in order to perform both SEM and TEM observations.

Figures $6 \mathrm{a}$ and $6 \mathrm{~b}$ show SEM images of samples CL 0.3 and RS 0.3, respectively. Both microstructures appear as 


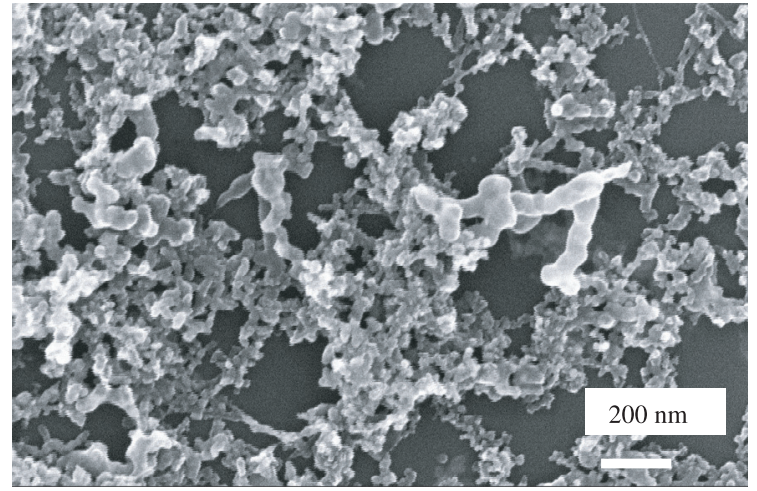

(a)

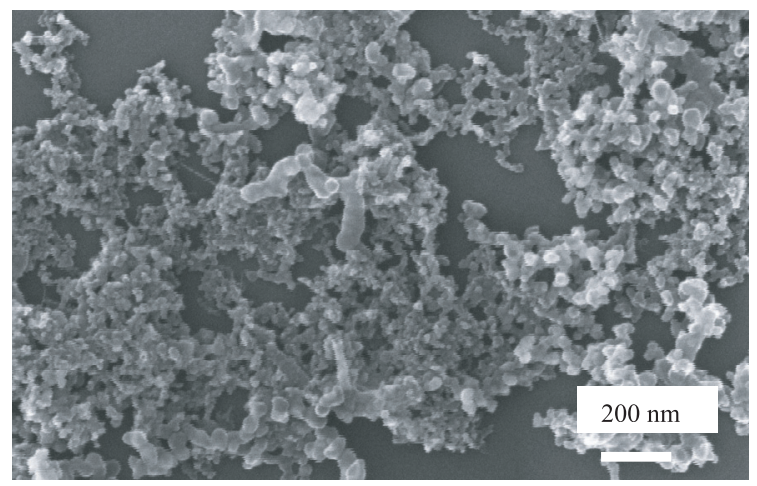

(b)

Fig. 6. SEM micrographs of (a) CL 0.3 and (b) RS 0.3 samples.

a complex spongy mixture of elongated or fibrous structures (several hundreds of $\mathrm{nm}$ in length) agglomerated with globular particles (several tens of nm in diameter).

A deeper insight into the microstructure of the soots is given by the TEM observations. Figure 7a shows a typical micrograph of the microstructure of the CL 0.3 sample. Both the globular and fibrous structures previously seen by SEM are clearly revealed, and exhibit a smooth appearance. These structures are attributed to an amorphous carbon gangue which constitutes the major volume fraction of the sample. Inside this amorphous gangue, some black features are clearly visible. These are thought to correspond to small crystalline nano-particles, measuring between 5 and $10 \mathrm{~nm}$, and irregularly dispersed in the amorphous gangue.

To support this interpretation, the electron diffraction pattern corresponding to Figure 7a is shown in Figure 7b. It exhibits two wide rings characteristic of an amorphous phase, and a narrow and intense ring characteristic of the presence of crystallites. The two wide rings correspond both to the carbon amorphous gangue and to the carbon/formvar film which also contributes to the diffraction pattern. The narrow ring corresponds to a lattice spacing of about $0.202 \mathrm{~nm}$. This spacing fits quite well with the main diffraction peak previously observed by X-ray diffraction (Sect. 3.1). As previously indicated, it could correspond to the more intense diffraction ring of the five Fe-C compounds (C-graphite, $\alpha$-Fe, $\gamma$-Fe, $\mathrm{Fe}_{3} \mathrm{C}$ or $\mathrm{Fe}_{5} \mathrm{C}_{2}$ ).

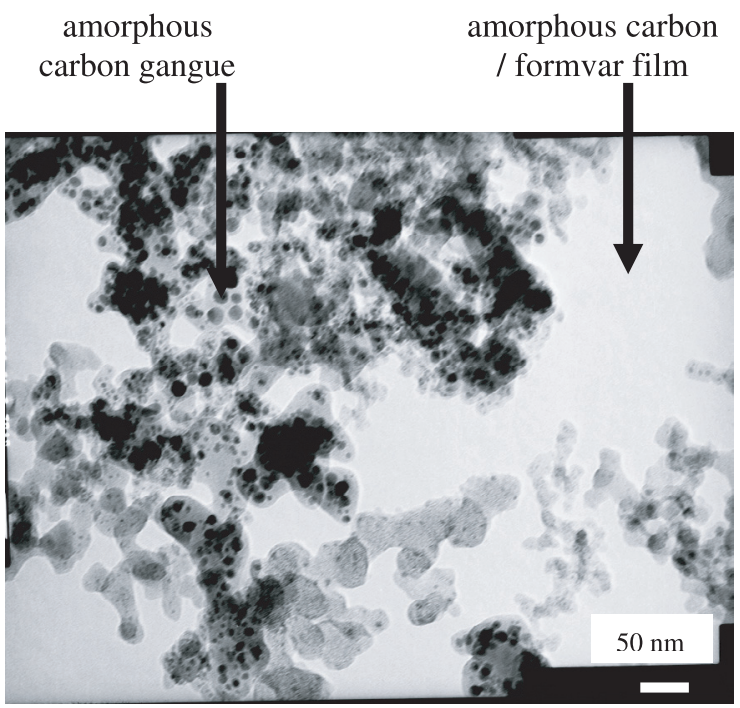

(a)

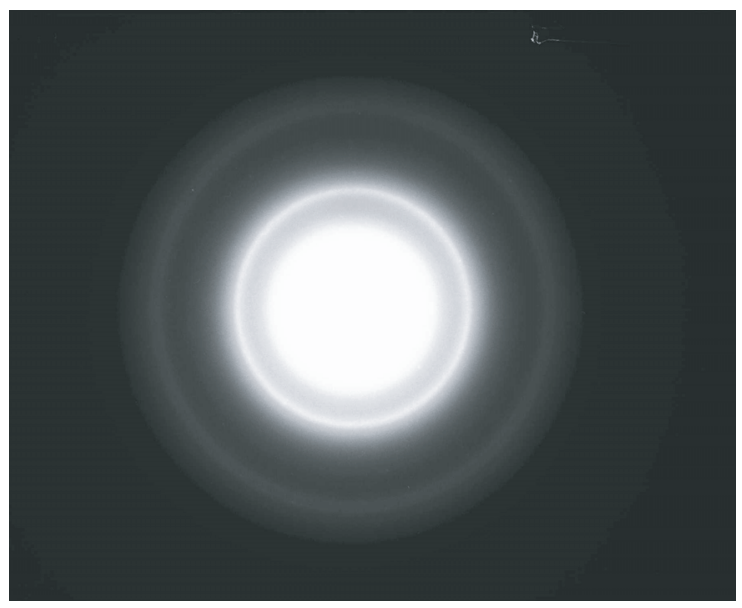

(b)

Fig. 7. (a) TEM micrograph of sample CL 0.3, (b) corresponding electron diffraction pattern.

Again, the lack of visible additional diffraction rings is an obstacle to obtaining more information on the presence of these compounds by diffraction analysis.

In addition to the amorphous gangue, some straight and elongated nanotubes are also sometimes observed in this sample (Fig. 8), but these objects are rather rare. Their diameter is about $7 \mathrm{~nm}$. From this diameter, it can be inferred that they correspond to multiwall nanotubes $[17,18]$.

The typical microstructure of sample RS 0.3 is shown in the electron micrograph of Figure 9a. The microstructure exhibits general features quite similar to sample CL 0.3: presence of an amorphous carbon gangue containing small nanocrystallites, with a comparable size. In agreement with these observations, the corresponding electron diffraction pattern shown in Figure 9b does not reveal significant differences with sample CL 0.3 .

However, a close inspection at a larger scale of the microstructure of sample RS 0.3 allowed to evidence two 


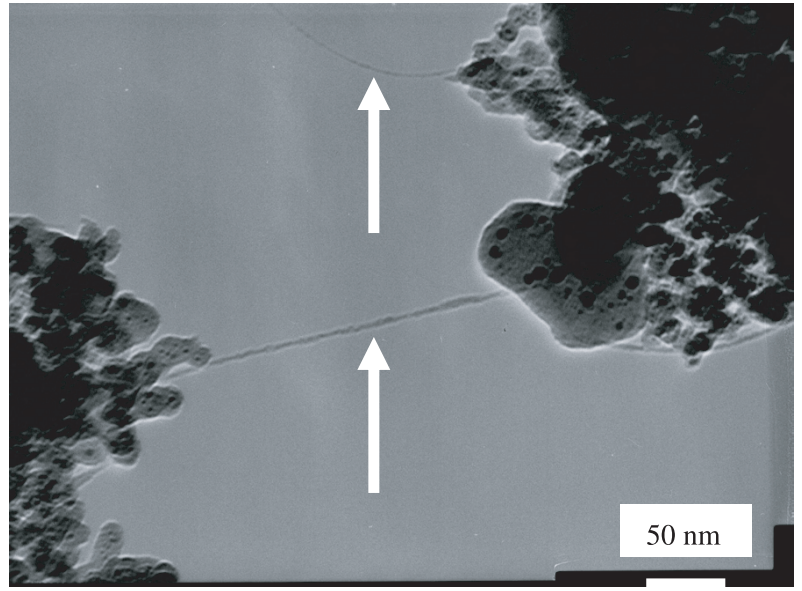

Fig. 8. TEM micrograph of sample CL 0.3 showing nanotubes (arrows).

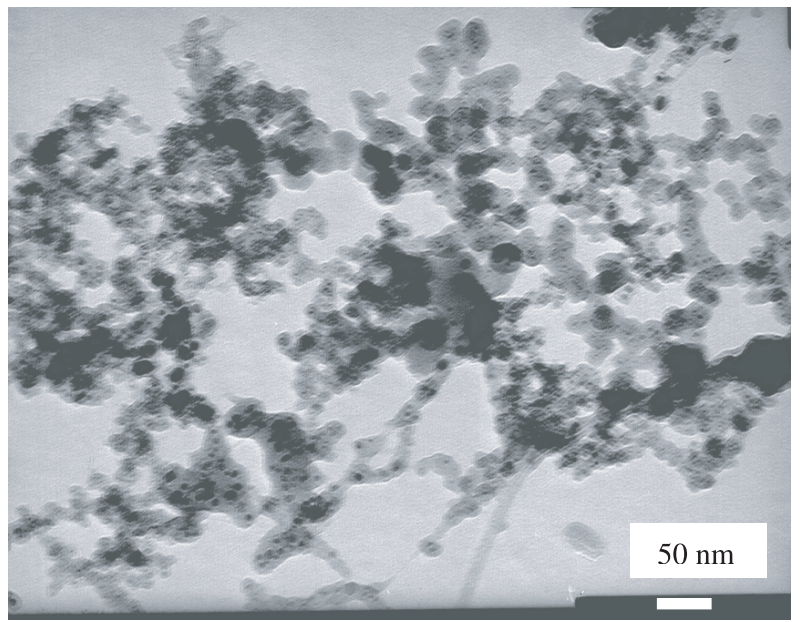

(a)

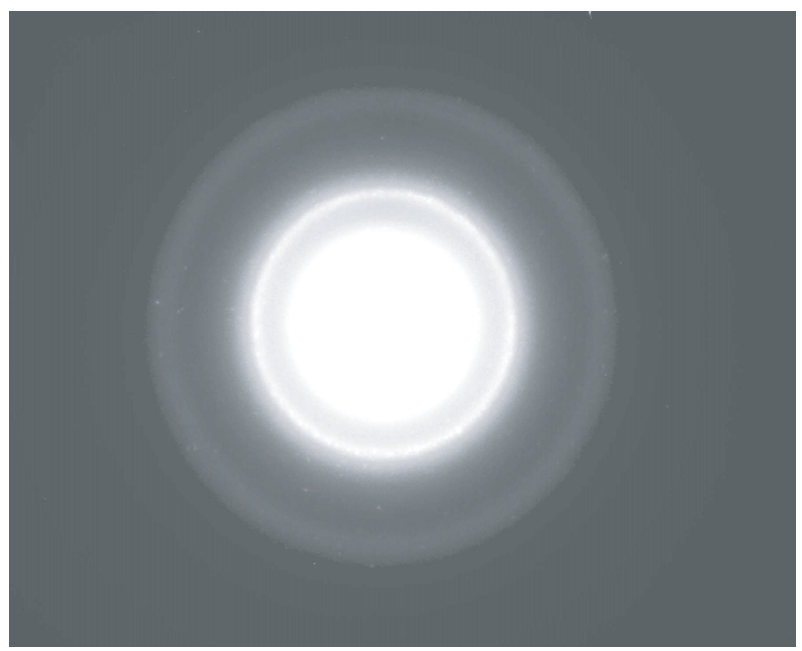

(b)

Fig. 9. (a) TEM micrograph of sample RS 0.3, (b) corresponding electron diffraction pattern.

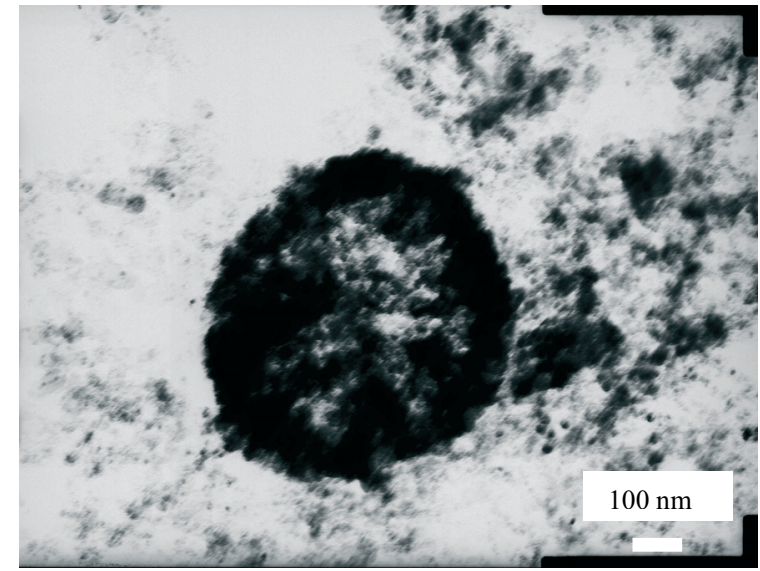

(a)

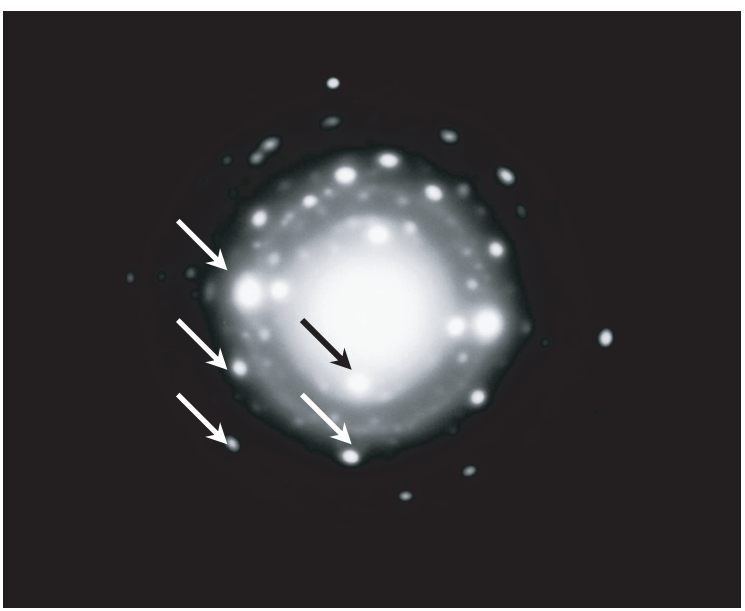

(b)

Fig. 10. (a) TEM micrograph of sample RS 0.3 showing the presence of a large crystallised particle, (b) example of complex composite electron diffraction pattern showing the presence of C-graphite (arrows) and other non indexed phases.

particular features, compared to sample CL 0.3. First, no nanotube could be found in the sample. Secondly, relatively large particles, with a typical size of some hundreds of nm, could be reproductibly detected from place to place in the sample. Their shape is often globular or lenticular (Fig. 10a). The electron diffraction patterns of these particles mainly consist of spots, indicating the crystalline nature of these particles. However, the patterns are often complex (Fig. 10b) and difficult to index. They correspond to composite superpositions of several patterns of individual monocrystals. Some of them can be indexed, thus indicating the presence of $\mathrm{C}$-graphite, $\alpha$-Fe and $\mathrm{Fe}_{3} \mathrm{C}$ in the particles.

The presence of these large particles, present in the RS 0.3 sample (taken $3 \mathrm{~cm}$ from the anode) and not found in the CL 0.3 sample (taken $30 \mathrm{~cm}$ from the anode) is attributed to a simple ballistic effect. During the deposition process, it is possible that the large particles are intercepted by the water-cooled copper cylinder located 


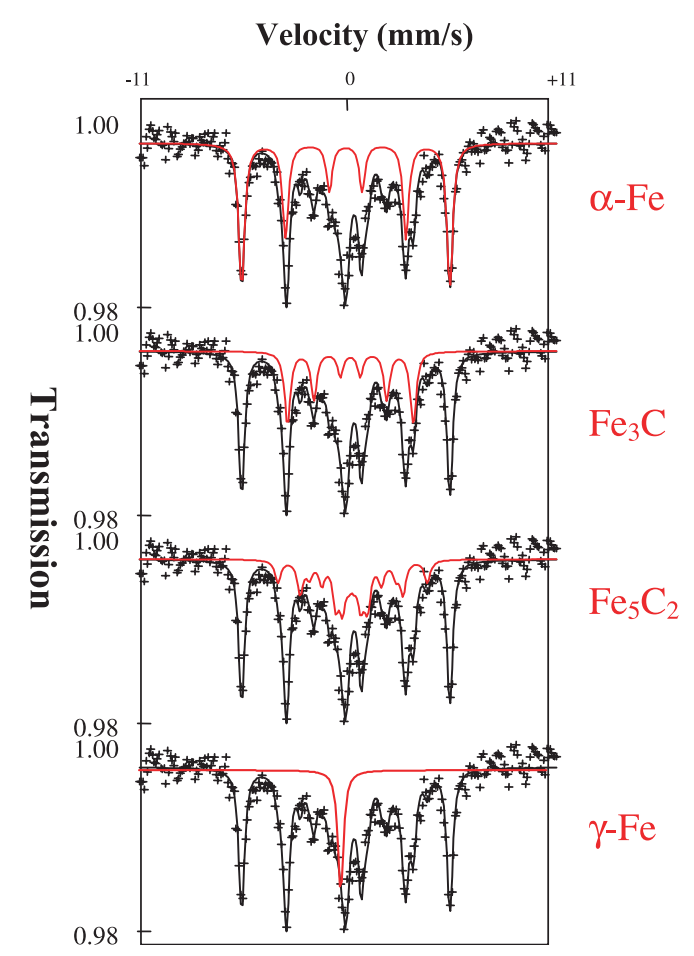

Fig. 11. Room temperature Mössbauer spectrum for RS 0.3 sample. For clarity, the spectrum is reproduced four times and a single sub-spectrum is shown at each time.

around the anode, while lighter particles could be rejected toward the Pyrex vessel.

\subsection{Mössbauer spectroscopy analysis}

\subsubsection{Nature and iron fraction of the compounds}

The room-temperature Mössbauer spectra for RS 0.3 , CL 0.3 and CL 0.6 samples are presented in Figures 11-13.

Taking into account all known phases of the Fe-C system, and in agreement with the X-ray diffraction results, we have fitted the three spectra using $\alpha$-Fe, $\gamma$-Fe, $\mathrm{Fe}_{3} \mathrm{C}$ and $\mathrm{Fe}_{5} \mathrm{C}_{2}$ phases. It is worth noting here that the compounds of $\alpha$-Fe, $\mathrm{Fe}_{3} \mathrm{C}$ and $\mathrm{Fe}_{5} \mathrm{C}_{2}$ phases are ferromagnetic (the corresponding Mössbauer spectrum is made up of sextuplets), while $\gamma$-Fe is paramagnetic at $300 \mathrm{~K}$ (the spectrum consists of a singlet).

The three spectra were initially fitted by using the published hyperfine parameters of $\alpha$-Fe, $\gamma$-Fe, $\mathrm{Fe}_{3} \mathrm{C}$ and $\mathrm{Fe}_{5} \mathrm{C}_{2}$ phases [19-21] (Tab. 3). After refinement, the fitted values of isomer shift and hyperfine field of the four phases are very close to values already published (Tab. 4). These results, obtained from Mössbauer analysis, clearly confirm the presence of the four phases as initially suggested by $\mathrm{X}$-ray diffraction and TEM experiments. As a result of the fitting procedure, the percentage of each phase existing in each sample could be estimated and is reported in Table 5.

One notices that the place of the samples in the reactor has a considerable influence. Indeed, the water-cooled copper cylinder sample (RS 0.3) contains more $\alpha$-Fe phase

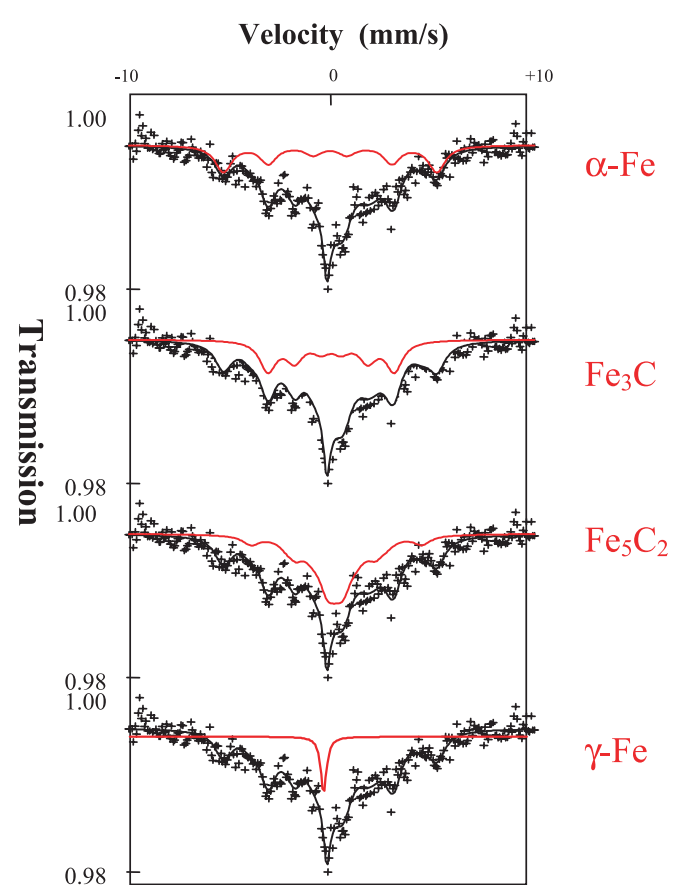

Fig. 12. Room temperature Mössbauer spectrum for CL 0.3 sample. For clarity, the spectrum is reproduced four times and a single sub-spectrum is shown at each time.

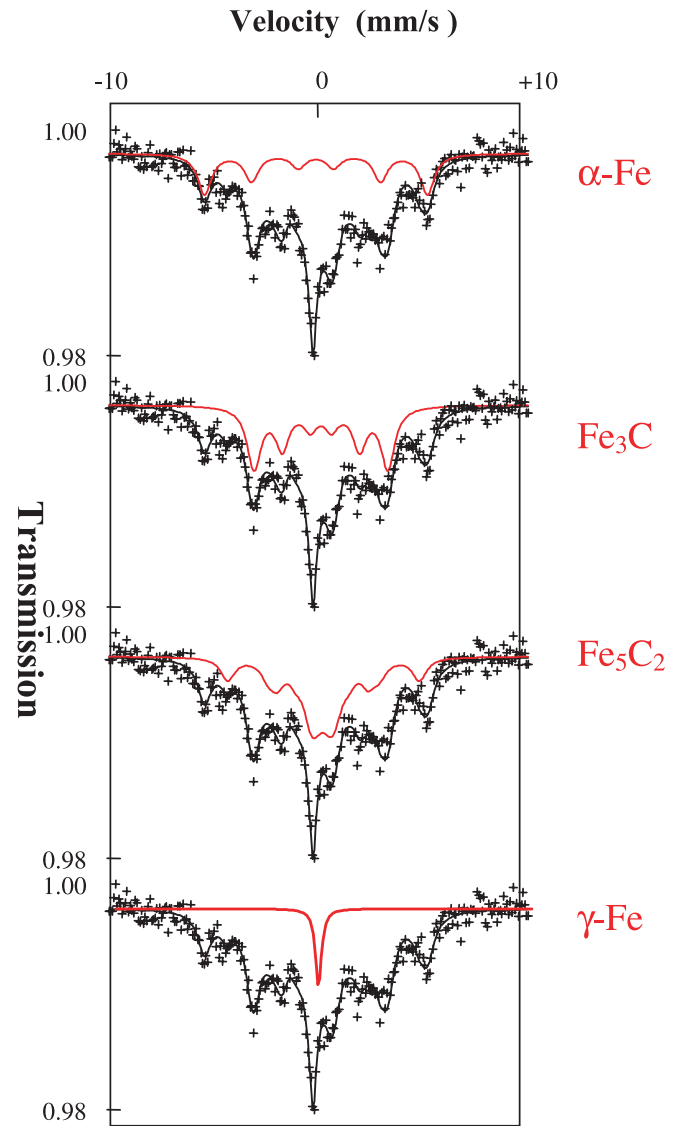

Fig. 13. Room temperature Mössbauer spectrum for CL 0.6 sample. For clarity, the spectrum is reproduced four times and a single sub-spectrum is shown at each time. 
Table 3. Literature values [19-21] of isomer shift and hyperfine field of the different iron-bearing phases.

\begin{tabular}{lll}
\hline Phase & Isomer shift $(\mathrm{mm} / \mathrm{s})$ & Hyperfine field (Tesla) \\
\hline$\alpha$-Fe & $0.00 \pm 0.01$ & $33.0 \pm 0.2$ \\
$\gamma$-Fe & $-0.09 \pm 0.01$ & 0.0 \\
$\mathrm{Fe}_{3} \mathrm{C}$ & $0.29 \pm 0.01$ & $20.8 \pm 0.2$ \\
\hline \multirow{2}{*}{$\mathrm{Fe}_{5} \mathrm{C}_{2}$} & $0.35 \pm 0.01$ & $22.2 \pm 0.2$ \\
& $0.30 \pm 0.01$ & $18.4 \pm 0.2$ \\
& $0.30 \pm 0.01$ & $11.0 \pm 0.2$ \\
\hline
\end{tabular}

Table 4. Hyperfine parameters deduced from the fitting of Mössbauer spectra to different phases (the $\mathrm{Fe}_{5} \mathrm{C}_{2}$ phase was fitted using 3 iron sites). $I S$ is the isomer shift, $H$ is the hyperfine field and $W$ is the half line-width.

\begin{tabular}{|c|c|c|c|c|}
\hline & Phase & $I S(\mathrm{~mm} / \mathrm{s})$ & $H$ (Tesla) & $W(\mathrm{~mm} / \mathrm{s})$ \\
\hline \multirow{6}{*}{ RS 0.3} & $\alpha-\mathrm{Fe}$ & $-0.01 \pm 0.01$ & $33.2 \pm 0.2$ & $0.18 \pm 0.01$ \\
\hline & $\gamma-\mathrm{Fe}$ & $-0.09 \pm 0.01$ & $0.0 \pm 0.2$ & $0.18 \pm 0.01$ \\
\hline & $\mathrm{Fe}_{3} \mathrm{C}$ & $0.23 \pm 0.01$ & $20.1 \pm 0.2$ & $0.18 \pm 0.01$ \\
\hline & $\mathrm{Fe}_{5} \mathrm{C}_{2}$ & $0.35 \pm 0.01$ & $23.9 \pm 0.2$ & $0.18 \pm 0.01$ \\
\hline & $\mathrm{Fe}_{5} \mathrm{C}_{2}$ & $0.30 \pm 0.01$ & $16.4 \pm 0.2$ & $0.18 \pm 0.01$ \\
\hline & $\mathrm{Fe}_{5} \mathrm{C}_{2}$ & $0.30 \pm 0.01$ & $5.1 \pm 0.2$ & $0.18 \pm 0.01$ \\
\hline \multirow{6}{*}{ CL 0.3} & $\alpha-\mathrm{Fe}$ & $0.04 \pm 0.01$ & $32.9 \pm 0.2$ & $0.5 \pm 0.01$ \\
\hline & $\gamma-\mathrm{Fe}$ & $0.34 \pm 0.01$ & $0.0 \pm 0.2$ & $0.18 \pm 0.01$ \\
\hline & $\mathrm{Fe}_{3} \mathrm{C}$ & $0.09 \pm 0.01$ & $19.5 \pm 0.2$ & $0.5 \pm 0.01$ \\
\hline & $\mathrm{Fe}_{5} \mathrm{C}_{2}$ & $0.35 \pm 0.01$ & $26.3 \pm 0.2$ & $0.5 \pm 0.01$ \\
\hline & $\mathrm{Fe}_{5} \mathrm{C}_{2}$ & $0.30 \pm 0.01$ & $12.3 \pm 0.2$ & $0.5 \pm 0.01$ \\
\hline & $\mathrm{Fe}_{5} \mathrm{C}_{2}$ & $0.30 \pm 0.01$ & $3.0 \pm 0.2$ & $0.5 \pm 0.01$ \\
\hline \multirow{6}{*}{ CL 0.6} & $\alpha-\mathrm{Fe}$ & $-0.01 \pm 0.01$ & $33.2 \pm 0.2$ & $0.4 \pm 0.01$ \\
\hline & $\gamma-\mathrm{Fe}$ & $-0.14 \pm 0.01$ & $0.0 \pm 0.2$ & $0.18 \pm 0.01$ \\
\hline & $\mathrm{Fe}_{3} \mathrm{C}$ & $0.23 \pm 0.01$ & $19.9 \pm 0.2$ & $0.4 \pm 0.01$ \\
\hline & $\mathrm{Fe}_{5} \mathrm{C}_{2}$ & $0.35 \pm 0.01$ & $28.5 \pm 0.2$ & $0.4 \pm 0.01$ \\
\hline & $\mathrm{Fe}_{5} \mathrm{C}_{2}$ & $0.30 \pm 0.01$ & $13.6 \pm 0.2$ & $0.4 \pm 0.01$ \\
\hline & $\mathrm{Fe}_{5} \mathrm{C}_{2}$ & $0.30 \pm 0.01$ & $3.7 \pm 0.2$ & $0.4 \pm 0.01$ \\
\hline
\end{tabular}

Table 5. Percentage of Fe atoms, as deduced from Mössbauer spectra, in the different phases of the samples.

\begin{tabular}{llll}
\hline Phase/Sample & RS 0.3 & CL 0.3 & CL 0.6 \\
\hline & $\%$ & $\%$ & $\%$ \\
$\alpha$-Fe & $42 \pm 2$ & $25 \pm 2$ & $22 \pm 2$ \\
$\gamma$-Fe & $8 \pm 2$ & $4 \pm 2$ & $5 \pm 2$ \\
$\mathrm{Fe}_{3} \mathrm{C}$ & $22 \pm 2$ & $29 \pm 2$ & $34 \pm 2$ \\
$\mathrm{Fe}_{5} \mathrm{C}_{2}$ & $28 \pm 2$ & $42 \pm 2$ & $39 \pm 2$ \\
\hline
\end{tabular}

fraction than the Pyrex vessel samples (CL 0.3), and conversely the RS 0.3 sample contains fewer carbides $\left(\mathrm{Fe}_{5} \mathrm{C}_{2}\right.$ and $\mathrm{Fe}_{3} \mathrm{C}$ ) than the CL 0.3 samples. One also notes that the place of the samples has only very little influence on the $\gamma$-Fe phase fraction in the sample.

\subsubsection{Effect of the particle size on Mössbauer spectra}

The location of the sample in the reactor has a drastic effect on the general aspect of the Mössbauer spectra. In fact, the spectrum of sample RS 0.3 presents narrow lines while the spectra corresponding to CL samples present broad lines. These effects also clearly appear from the half line-widths in Table 4. Sample CL 0.3 has a large half linewidth of $0.5 \mathrm{~mm} / \mathrm{s}$ which is characteristic of small particles
Table 6. Percentage of Fe atoms, as deduced from Mössbauer spectrum, in the different phases forming the large particles in sample RS 0.3 .

\begin{tabular}{ll}
\hline Phase & $\%$ \\
\hline$\alpha$-Fe & $53 \pm 2$ \\
$\gamma$-Fe & $7 \pm 2$ \\
$\mathrm{Fe}_{3} \mathrm{C}$ & $22 \pm 2$ \\
$\mathrm{Fe}_{5} \mathrm{C}_{2}$ & $18 \pm 2$ \\
\hline
\end{tabular}

distributed in size. The RS 0.3 spectrum, however, has a much smaller half line-width of $0.18 \mathrm{~mm} / \mathrm{s}$, characteristic of larger particles more representative of the bulk. These effects are in agreement with previously quoted TEM observations which indicate the presence of nanocrystallites in amorphous gangue for CL 0.3 , and the additional existence of larger monocrystalline particles for RS 0.3.

On this basis, the RS 0.3 Mössbauer spectrum was analysed in a more refined way: it was considered to be the sum of two contributions corresponding to (i) the spectrum of CL 0.3 consisting of nanoparticles of the four ironbearing phases with broad lines, (ii) the spectrum corresponding to the large particles with a typical size of some hundreds of $\mathrm{nm}$ with narrow lines. As a consequence, the spectrum of CL 0.3 was subtracted (as a noise) from the spectrum of RS 0.3 [22]. The difference-spectrum obtained is characteristic of the large particles and was fitted by the hyperfine parameters of $\alpha-\mathrm{Fe}, \gamma-\mathrm{Fe}, \mathrm{Fe}_{3} \mathrm{C}$ and $\mathrm{Fe}_{5} \mathrm{C}_{2}$ phases. As a result of the fit, the percentage of each phase existing in the large particles of RS 0.3 sample could be estimated and is reported in Table 6 . The results indicate that $\alpha-\mathrm{Fe}$ is the major phase in the large particles. The relative contribution of the small nanoparticles to the spectrum of RS 0.3 is about $35 \%$.

From X-ray diffraction data [16], the volumic density of the Fe-atoms in each iron-bearing phase has been calculated. The values vary slightly from about $84 \mathrm{Fe}-$ atoms $/ \mathrm{nm}^{3}$ for both $\alpha$-Fe and $\gamma$-Fe, to 77 and $75 \mathrm{Fe}-$ atoms $/ \mathrm{nm}^{3}$ for the carbides $\mathrm{Fe}_{3} \mathrm{C}$ and $\mathrm{Fe}_{5} \mathrm{C}_{2}$ respectively. In a rough approximation, this density can be considered to be constant. This means that the volume fraction of each phase, both in the large particles and in the nanoparticles, is about the same as the Fe-atomic fraction given in Tables 5 and 6 . A direct consequence is that the volume fraction of nanoparticles is also about $35 \%$ of the total volume. It is worth noting that these values only concern the iron-bearing phases, and take into account neither the iron-free C-graphite fraction nor the amorphous carbon fraction, which do not give any signal in Mössbauer spectrometry. Assuming, in agreement with X-ray diffraction analysis (Sect. 3.1), that the C-graphite volume fraction in the particles is low and can be neglected, the ratio of the number of small nanoparticles to large particles can be directly calculated from these data. For nanoparticles in the range $5-10 \mathrm{~nm}$ and for large particles of some hundreds of nm (Sect. 3.2), this ratio is estimated to be several hundreds of thousands. 


\subsubsection{Influence of the helium pressure on the state} of crystallization

For two CL samples, the intensity and the narrowness of the lines increase as the helium pressure increases (Tab. 4) suggesting that the CL 0.6 sample is constituted of larger nano-crystallites than the CL 0.3 sample. This behavior indicates, therefore, that the pressure of helium under the Pyrex vessel during the synthesis has an influence on the state of crystallization of the final product.

Finally, an increase in the helium gas pressure under the Pyrex vessel leads to a slight increase in $\mathrm{Fe}_{3} \mathrm{C}$ phase and to the decrease of $\alpha$-Fe and $\mathrm{Fe}_{5} \mathrm{C}_{2}$ phases.

\section{Conclusion}

This work focuses on the investigation of the nature, fraction and microstructure of the various compounds of carbon and iron synthesized by the DC arc discharge method with the composite anode, as a function of two parameters: the place in the reactor and the gas pressure.

First, the soot obtained on the Pyrex vessel consists of the same five phases (C-graphite, $\alpha$-Fe, $\gamma$-Fe, $\mathrm{Fe}_{3} \mathrm{C}$ and $\mathrm{Fe}_{5} \mathrm{C}_{2}$ ) whatever the helium gas pressure and whatever the place in the reactor. Secondly, one notices that the place in the reactor has a considerable influence. The Fe-C compounds in the Pyrex vessel samples (CL) seems to be present only in the form of nanoparticles embedded in an amorphous gangue, while the water-cooled copper cylinder sample (RS) contains, in addition to these nanoparticles, large composite crystalline particles. Moreover, the RS sample contains more $\alpha$-Fe phase fraction than the samples (CL), particularly in the large particles. Conversely the RS sample contains fewer carbides $\left(\mathrm{Fe}_{3} \mathrm{C}\right.$ and $\left.\mathrm{Fe}_{5} \mathrm{C}_{2}\right)$ than the CL samples. However, the place in the reactor has only very little influence on the $\gamma$-Fe phase fraction in the sample. Finally, an increase in the helium gas pressure under the Pyrex vessel leads to a slight increase in the fraction of the $\mathrm{Fe}_{3} \mathrm{C}$ phase and to the decrease of $\alpha$-Fe and $\mathrm{Fe}_{5} \mathrm{C}_{2}$ phases.

We would like to thank Dilys Moscato for helping with the English of this manuscript.

\section{References}

1. H.W. Kroto, J.R. Heath, S.C. O'Brien, R.F. Curl, R.E. Smalley, Nature 318, 162 (1985)

2. W. Krätschmer, L.D. Lamb, K. Fostiropoulos, D.R. Huffman, Nature 347, 354 (1990)

3. C. Guerret-Piécourt, Y. Le Bouar, A. Loiseau, H. Pascard, Nature 372, 761 (1994)

4. S. Iijima, Nature 354, 56 (1991)

5. H. Lange, M. Sioda, A. Huczko, Y.Q. Zhu, H.W. Kroto, D.R.M. Walton, Carbon 41, 1617 (2003)

6. S. Seraphin, D. Zhou, J. Jiao, J.C. Withers, R. Loutfy, Nature 362, 503 (1993)

7. S. Cui, P. Scharff, C. Siegmund, D. Schneider, K. Risch, S. Klötzer, L. Spiess, H. Romanus, J. Schawohl, Carbon 42, 931 (2004)

8. Zujin Shi, Yongfu Lian, Fu Hui Liao, Xihuang Zhou, G. Zhennan, Y. Zhang, S. Iijima, Hongdong Li, Kwok To Yue, Shu-Lin Zhang, J. Phys. Chem. Solids 61, 1031 (2000)

9. N. Demoncy, H. Pascard, A. Loiseau, N. Brun, C. Colliex, O. Stéphan, Synthetic Metals 10, 2380 (1999)

10. H. Pascard, Atomic and Molecular Wires (Kluwer Academic Publishers, 1997), 99

11. P.M. Ajayan, O. Stephan, Ph. Redlich, C. Colliex, Nature 375, 564 (1995)

12. A. Loiseau, H. Pascard, Chem. Phys. Lett. 256, 246 (1996)

13. S. Subramoney, R.S. Ruoff, D.C. Lorents, B. Chan, R. Mathotra, M.J. Dyer, K. Parvin, Carbon 32, 507 (1994)

14. P.M. Ajayan, C. Colliex, J.M. Lambert, P. Bernier, L. Barbedette, M. Tencé, O. Stephan, Phys. Rev. Lett. 72, 1722 (1994)

15. J. Teillet, F. Varret, MOSFIT Program, 1983 (unpublished)

16. Joint Committee on Powder Diffraction Standards, International Center for Diffraction Data. File number 00006-0696 for $\alpha$-Fe; File number 00-052-0512 for $\gamma$-Fe; File number 03-065-6212 for graphitic C; File number 00-0350772 for $\mathrm{Fe}_{3} \mathrm{C}$; File number 01-089-8968 for $\mathrm{Fe}_{5} \mathrm{C}_{2}$.

17. P. Petit, A. Loiseau, C. R. Phys. 4, 967 (2003)

18. T. Ebbesen, Phys. Today 49, 26 (1996)

19. H. Bernas, I.A. Campbell, R. Fruchart, J. Phys. Chem. Solids 28, 17 (1967)

20. T. Shinjo, F. Itoh, H. Takaki, Y. Nakamura, N. Shikazono, J. Phys. Soc. Jpn 19, 1252 (1964)

21. M. Ron, H. Shechter, A.A. Hirsch, S. Niedzwiedz, Phys. Lett. 20, 481 (1966)

22. A. Fnidiki, J. Juraszek, J. Teillet, Appl. Phys. Lett. 75, 1296 (1999) 